\title{
EFICIENCIA DE FUNGICIDAS NO CONTROLE DA MANCHA PRETA EM AMENDOIM RASTEIRO
}

Guilherme Xavier Lúcio dos Santos; Monica Helena Martins²; Paulo Sérgio Cordeiro Junior³; Everton Luís Finoto ${ }^{4}$

${ }^{1}$ Engenheiro Agrônomo, Bolsista de Aperfeiçoamento Técnico Fundag, APTA, guilhermexaviersantos@hotmail.com; ${ }^{2}$ Engenheira Agrônomo, Bolsista de Aperfeiçoamento Técnico Fundag, APTA; ${ }^{3}$ Engenheiro Agrônomo, mestrando em Produção Vegetal UNESP/FCAV; ${ }^{4}$ Pesquisador Cientíco, Dr., APTA Regional - Polo Centro Norte, Pindorama, SP.

RESUMO: Dentre as doenças mais importantes para a cultura do amendoim no Estado de São Paulo encontra-se a mancha preta. Objetivou-se com o presente trabalho avaliar a eficiência de diferentes fungicidas e formulações, isolados ou associados no controle de mancha preta do amendoim IAC OL3 em Pindorama-SP, na safra 2016/2017. Utilizou-se delineamento em blocos casualizados, com 4 repetições e 7 tratamentos. Os tratamentos foram constituídos por diferentes formulações, princípios ativos e intervalos de aplicações de fungicidas: 1- CHLOROTHALONIL WG; 2- CHLOROTHALONIL WG (28 dias int.); 3- CHLOROTHALONIL SC; 4- (PIRACLOSTROBINA+EPOXICONAZOL); 5(PIRACLOSTROBINA+EPOXICONAZOL) + CHLOROTHALONIL $\quad$ SC; $6-$ (PIRACLOSTROBINA+EPOXICONAZOL) + CHLOROTHALONIL WG; 7- Testemunha (sem aplicação de fungicida). A combinação entre (PIRACLOSTROBINA+ POXICONAZOL) + CHLOROTHALONIL SC, é eficiente no controle de mancha preta do amendoim ao longo do desenvolvimento da cultura.

Palavras-Chave: Arachis hypogaea; Cercosporidium personatum; IAC OL3; produtividade.

\section{INTRODUÇÃO}

Conhecido mundialmente pela sua importante fonte de proteína e óleo, o amendoim (Arachis hypogaea) cumpre um papel importante na economia do país, muito em função da sua grande diversidade de consumo (SANTOS et al., 1997). O amendoim é considerado a quarta maior cultura oleaginosa no mundo, com $10 \%$ do total da safra mundial de oleaginosas, estando atrás da soja, algodão e colza. A produção mundial ultrapassa 30 milhões de toneladas, e as áreas de cultivo distribuem-se em diversos continentes. Os principais países produtores são China, Índia, Estados Unidos, Nigéria, Indonésia e Senegal. China, Estados Unidos e Argentina são os principais exportadores de amendoim em grãos, mas os dois primeiros também são grandes consumidores (USDA, 2009). O Estado de São Paulo destaca-se na produção brasileira de amendoim, como maior produtor nacional, com aproximadamente $93 \%$ da área plantada e quase 95\% de toda a produção do país (CONAB, 2018). 
$\mathrm{Na}$ cultura do amendoim podem ocorrer várias doenças causadas por fungos que afetam tanto a parte aérea, como também o sistema radicular. A incidência de doenças foliares pode ser fator limitante para produtividade da cultura do amendoim. A doença de maior expressão e potencial de danos para o amendoim nas condições do Estado de São Paulo é conhecida como mancha preta (Cercosporidium personatum). Os principais problemas podem ocorrer durante o desenvolvimento da cultura. A mancha preta tem sido a mais prevalente na cultura do amendoim no estado de São Paulo (MORAES E GODOY, 1985; MORAES et al., 1988; 1994).

Objetivou-se neste trabalho avaliar a eficiência de diferentes fungicidas e formulações, isolados ou associados, no controle de mancha preta do amendoim IAC OL3, no município de Pindorama-SP, na safra 2017/18.

\section{MATERIAL E MÉTODOS}

O experimento foi conduzido Apta Regional - Polo Centro Norte, vinculado a Agência Paulista de Tecnologia do Agronegócio, pertencente à Secretaria da Agricultura e Abastecimento do Estado de São Paulo, localizado no município de Pindorama, SP. A área onde foi conduzido o experimento possui solo caracterizado como argissolo eutrófico vermelho-amarelo, considerado profundo, com horizonte A arenoso e horizonte B textural com alta fertilidade e topografia plana. Conforme classificação de Koppen, o clima enquadra-se no tipo Aw, definido como tropical úmido com estação chuvosa no verão e seca no inverno.

Utilizou-se delineamento em blocos casualizados, com 5 repetições e 7 tratamentos (Fungicidas) expostos na Tabela 1. A cultivar utilizada foi a IAC OL3. As unidades experimentais foram constituídas de 4 linhas de 10 metros de comprimento, espaçadas a 0,90 metros e a densidade de semeadura foi de 20 sementes por metro. Para a dosagem dos produtos, foram seguidas as recomendações dos fabricantes: Bravonil Ultrex ${ }^{\circledR}$ : 1,5 Kg.ha ${ }^{-1}$; Opera®: 0,6 L.ha ${ }^{-1}$ e NTX 9900: 3,5 L $\mathrm{ha}^{-1}$. As aplicações dos fungicidas foram realizadas aos 60 DAS (dias após a semeadura), 75 DAS, 90 DAS, 105 DAS e 120 DAS utilizando pulverizador costal elétrico na vazão de 300 L.ha $^{-1}$, equipados com pontas de pulverização XP-1100 $110^{\circ}$ duplo leque. A avaliação da mancha-preta foi realizada momentos antes da aplicação dos fungicidas, sempre nas linhas centrais da unidade experimental, através de uma escala diagramática com notas de sintomas visuais variando de 1 a 9 . Esta escala considera a quantidade de mancha preta por folha, o número de folhas com lesões e a desfolha ao longo de um dos ramos primários da planta (SUBRAHMANYAM et al., 1982). No final do ciclo a colheita foi realizada avaliação nas duas linhas centrais, descartando 2,5 metros das duas extremidades de cada unidade, considerando $9 \mathrm{~m}^{2}$ para obtenção do estande final de plantas e produtividade em $\mathrm{kg}$ $\mathrm{ha}^{-1}$.

Os dados foram submetidos à análise de variância pelo teste $\mathrm{F}$, para efeito de significância dos tratamentos e as médias comparadas pelo teste de Tukey a $5 \%$ de probabilidade. 
Tabela 1. Fungicidas e seus ativos, comparados na eficiência de controle de mancha preta na cultura do amendoim, Pindorama, SP, safra 2017/2018.

\begin{tabular}{lllcc}
\hline $\mathbf{N}^{\mathbf{0}}$ & NOME TRATAMENTO & PRINCÍPIO ATIVO & FORMULAÇÃO & DOSE \\
\hline 1 & Bravonil Ultrex & CHLOROTHALONIL & $(\mathrm{WG})$ & $(825 \mathrm{~g} / \mathrm{kg})$ \\
2 & $\begin{array}{l}\text { Bravonil Ultrex } \\
\text { (Intervalo 28 dias) }\end{array}$ & CHLOROTHALONIL & $(\mathrm{WG})$ & $(825 \mathrm{~g} / \mathrm{kg})$ \\
3 & NTX 9900 & CHLOROTHALONIL & $(\mathrm{WG})$ & $(500 \mathrm{~g} / \mathrm{L})$ \\
4 & Opera & PIRACLOSTROBINA & $(133 \mathrm{~g} / \mathrm{L})+$ \\
5 & Opera + NTX 9900 & $\begin{array}{l}\text { PIRACLOST. + EPOXIC. }+ \\
\text { CHLOROTHALONIL }\end{array}$ & $(\mathrm{WG})$ & $(50 \mathrm{~g} / \mathrm{L})$ \\
6 & Opera + Bravonil Ultrex & $\begin{array}{l}\text { PIRACLOST. + EPOXICON. }+ \\
\text { CHLOROTHALONIL }\end{array}$ & \\
7 & TESTEMUNHA & & & \\
\hline
\end{tabular}

\section{RESULTADOS E DISCUSSÃO}

Houve diferença significativa entre os tratamentos com diferentes fungicidas/formulações para o controle e períodos de avaliação avaliações dos sintomas visuais de mancha preta do amendoim. Observou-se o aumento das notas dos sintomas visuais de mancha preta do amendoim ao longo do ciclo de desenvolvimento vegetativo e reprodutivo da cultura no tratamento testemunha, na qual não recebeu aplicação dos tratamentos (fungicidas), constatando-se a alta susceptibilidade da cultivar IAC OL3 a esta doença foliar (Tabela 2).

Desde o inicio das avaliações, aos 90 DAS, até o final do ciclo da cultura os tratamentos 3 (NTX 9900) e o tratamento 5 (NTX 9900 + Opera), apresentaram as menores notas de sintomas visuais, totalizando três avaliações dos tratamentos nas unidades experimentais, diferenciando-se dos demais tratamentos estudados.

O tratamento 2 (CHLOROTHALONIL em intervalo de 28 dias) e o tratamento 4 (Ópera) não se mostraram eficientes no controle de mancha preta do amendoim, tendo as maiores notas de sintomas visuais da doença, com relação aos demais tratamentos que receberam a aplicação de fungicidas, assemelhando-se, portanto, ao tratamento testemunha. 
16 e 17 de agosto de 2018, centro de convenções da FCAV/UNESP - Câmpus de Jaboticabal, SP

Tabela 2. Notas de sintomas de mancha preta da cultura do amendoim, em função dos diferentes tipos de fungicidas e épocas de avaliação da doença foliar, Pindorama, SP, safra 2017/2018

\begin{tabular}{llll}
\hline \multicolumn{1}{c}{ FUNGICIDAS } & 90 DAS & 105 DAP & 120 DAS \\
\hline 1- Bravonil Ultrex & $4,24 \mathrm{c}$ & $7,00 \mathrm{~b}$ & $7,88 \mathrm{~b}$ \\
2- Bravonil Ultrex (28 dias) & $6,52 \mathrm{~b}$ & $7,96 \mathrm{a}$ & $8,96 \mathrm{a}$ \\
3- NTX 9900 & $3,96 \mathrm{c}$ & $5,92 \mathrm{c}$ & $7,00 \mathrm{c}$ \\
4- Opera & $6,52 \mathrm{~b}$ & $8,24 \mathrm{a}$ & $9,00 \mathrm{a}$ \\
5- Opera + NTX 9900 & $3,84 \mathrm{c}$ & $5,24 \mathrm{c}$ & $7,16 \mathrm{c}$ \\
6- Opera + Bravonil Ultrex & $4,00 \mathrm{c}$ & $5,36 \mathrm{c}$ & $7,72 \mathrm{~b}$ \\
7- Testemunha & $7,24 \mathrm{a}$ & $8,12 \mathrm{a}$ & $9,00 \mathrm{a}$ \\
\hline \multicolumn{1}{c}{ Média Geral } & 5,25 & 6,83 & 8,10 \\
\hline \multicolumn{1}{c}{ DMS (5\%) } & 0,68 & 0,86 & 0,44 \\
\hline \multicolumn{1}{c}{ Teste F } & $97,67 * *$ & $48,21 * *$ & $80,98^{* *}$ \\
\hline \multicolumn{1}{c}{ C.V.(\%) } & 6,51 & 6,22 & 2,70 \\
\hline
\end{tabular}

Médias seguidas de mesma letra na coluna não diferem entre si pelo teste de Tukey $(p \geq 0,05) .{ }^{* *}$ Significativo ao nivel de $1 \%(0,01)$ de probabilidade

Os tratamentos para controle de mancha preta do amendoim apresentam influência significativa na produtividade de vagens de amendoim cultivar OL3 e também no estande final de plantas (Tabela 3).

O Tratamento 5 atingiu a maior produtividade em Kg.ha ${ }^{-1}$ com 3.998,80 Kg.ha ${ }^{-1}$, seguido pelo tratamento 3, com 3.735,60 Kg.ha ${ }^{-1}$. Os tratamentos contendo fungicida SC (suspensão concentrada), apresentaram produtividades superiores aos tratamentos contendo fungicida WG (granulado dispersível). Estes resultados corroboram com os obtidos por CORDEIRO JUNIOR et al., (2017).

Tabela 3. Estande final de plantas e produtividade do amendoim em função dos diferentes tipos de fungicidas, Pindorama, SP, safra 2017/2018

\begin{tabular}{llc}
\hline Fungicidas & Estande Final & Produtividade $\mathrm{Kg}^{-h^{-1}}$ \\
\hline 1- Bravonil Ultrex & $122.400 \mathrm{ab}$ & $3.175,60 \mathrm{c}$ \\
2- Bravonil Ultrex (28 dias) & $100.400 \mathrm{ab}$ & $1.524,40 \mathrm{~d}$ \\
3- NTX 9900 & $127.600 \mathrm{ab}$ & $3.735,60 \mathrm{ab}$ \\
4- Opera & $100.600 \mathrm{ab}$ & $1.590,20 \mathrm{~d}$ \\
5- Opera + NTX 9900 & $148.000 \mathrm{a}$ & $3.998,80 \mathrm{a}$ \\
6- Opera + Bravonil Ultrex & $125.600 \mathrm{ab}$ & $3.445,60 \mathrm{~b}$ \\
7- Testemunha & $82.800 \mathrm{~b}$ & $933,20 \mathrm{e}$ \\
\hline Média Geral & 115342,86 & 2629,05 \\
\hline DMS (5\%) & 49539,48 & 431,92 \\
\hline Teste F & $4,02 * *$ & $170,27 * *$ \\
\hline C.V. (\%) & 21,14 & 8,08 \\
\hline Medis
\end{tabular}

Médias seguidas de mesma letra não diferem entre si pelo teste de Tukey $(p \geq 0,05)$. ), ${ }^{* *}$ Significativo ao nivel de $1 \%(0,01)$ de probabilidade 


\section{CONCLUSÃO}

$\mathrm{O}$ uso de CHLOROTHALONIL SC isolado como também a e a combinação (PIRACLOSTROBINA+POXICONAZOL) + CHLOROTHALONIL SC é eficiente no controle de mancha preta ao longo do ciclo do amendoim.

\section{REFERENCIAS BIBLIOGRÁFICAS}

CONAB- Companhia Nacional de Abastecimento. Acompanhamento da safra brasileira 2018. v. 5 Safra 2017/18 - n. 10 - Décimo levantamento julho 2018. Disponível em: $<$ https://www.conab.gov.br/info-agro/safras/graos>. Acesso em 01/07/2018.

CORDEIRO JUNIOR, P.S.; FINOTO, E.L.; MARTINS, M.H.; SOUZA, T.M.; LAMANA, L.E.P. Eficiência de fungicidas no controle de mancha preta Cercosporidium personatum do amendoim na safra 2016/2017.

In. XIV Encontro sobre a cultura do amendoim, FCAV/UNESP, Jaboticabal-SP, Anais...,p. 42-46, 2017.

MORAES, S.A.; GODOY, I.J. Amendoim - Controle de Doenças. In: ZAMBOLIM, L.; VALE, F.X.R. (Ed.). Controle de doenças de plantas: Grandes culturas. Viçosa, Universidade Federal de Viçosa; Brasília, Ministério da Agricultura e do Abastecimento, 1997. v.1, p.1-49.

MORAES, S.A.; GODOY, I.J. Diferentes níveis de resistência a Cercosporidiumpersonatum em genótipos de Arachishypogaea. SummaPhytopathologica, v.11, p.74-86, 1985.

SUBRAHMANYAM, P.; MCDONALD, D.; GIBBONS, R. W.; NIGAM, S. N.; NEVILL; D.J. Resistance to rust and late leaf spot diseases in some genotypes of Arachishypogaea.Peanut Science, v.9, p.9-14, 1982.

SANTOS, R.C.; MELO FILHO, P.A.; BRITO, S.F.M.; MORAES, J.S. Fenologia de genótipos de amendoim dos tipos botânicos Valência e Virgínia. Pesquisa Agropecuária Brasileira, v.32, p.607$612,1997$.

USDA - FOREIGN AGRICULTURAL SERVICE. World AgriculturalProduction (Table 13). Disponível em: <http://www.ers.usda.gov/publications/fds>. Acesso em 06 jul. 2018. 